\title{
Comparison of Analytical Methods and Residue Patterns of Pymetrozine in Aster scaber
}

\author{
Ji-Hyung Hong $\cdot$ Cho-Rong Lee $\cdot$ Jong-Sung Lim • \\ Kyu-Seung Lee
}

Received: 19 May 2011/ Accepted: 2 September 2011/Published online: 16 September 2011

(c) The Author(s) 2011. This article is published with open access at Springerlink.com

\begin{abstract}
Residues of the polar pesticide pymetrozine were compared using two methods: hydromatrix and liquidliquid extraction (LLE). The biological half-life and the final residue level were investigated using Aster scaber over a 10-days cultivation period. The respective biological halflives of the pesticide were 4.2 and 3.5 days at the recommended and double dose. The final residue levels were 1.28 and $1.98 \mathrm{mg} \mathrm{kg}^{-1}$, respectively, at the same application rate of pymetrozine according to the GAP standard of the United Kingdom. Average recovery was higher with LLE than with the hydromatrix method. Dissipation curves of pymetrozine were influenced by the application amount and growth rate of A. scaber. The final residue level of pymetrozine could be predicted to be lower than the UK maximum residue limit for lettuce applying the GAP standard.
\end{abstract}

Keywords Pymetrozine - LLE - Hydromatrix ·

Growth rate

Pymetrozine [(E)-4,5-dihydro-6-methyl-4-(3-pyridylmethyleneamino)-1,2,4-triazin-3(2H)-one] (Fig. 1) is a novel selective insecticide that represents a new chemical class of insecticides with remarkable selectivity for plant-sucking insects such as aphids (Fuog et al. 1998; Cun et al. 2011). It acts in a unique way by interfering in the regulation of the nervous system for feeding behavior, which results in death of the insect due to starvation a few days after application (Bextine et al. 2004; Guoqing et al. 2009). The US

J.-H. Hong · C.-R. Lee · J.-S. Lim · K.-S. Lee ( $ه)$

Department of Bio-Environmental Chemistry,

Chungnam National University, 220 Kungdong Yusungku, Daejeon 305-764, Republic of Korea

e-mail:kslee@cnu.ac.kr
Environmental Protection Agency (EPA) has classified pymetrozine as a "likely" human carcinogen, and the data are insufficient to eliminate the need for a quantitative risk assessment. Because of the limited number of sites on which this pesticide is used, the low use rates, and low exposure, the actual risks to human health are below the level of concern (EPA 2000).

Aster scaber is an edible dicotyledonous plant in the family Asteraceae (Compositae), the same family as lettuce. The maximum residue limit (MRL) for pymetrozine on lettuce has been established in the United Kingdom at $2 \mathrm{mg} \mathrm{kg}^{-1}$ (HSE 2008). Several methods have been developed for analyzing pymetrozine residues in plants, such as an enzyme immune assay (ELA), liquid chromatography (LC) with UV/vis, diode array detection (DAD), and mass spectrometry (MS). However, the most frequently used method is LC with UV/vis DAD (Peter et al. 1996; Zhang et al. 2007). Polar pesticides like pymetrozine (log Kow, -0.18) and dinotefuran (log Kow, -0.549) are known to be difficult to analyze. Therefore, this study sought to reveal efficient analytical methods for detecting pymetrozine residues and examined the biological half-life and residue pattern of this pesticide in A. scaber during cultivation. At the same time, the final residue levels at harvest for A. scaber and lettuce were predicted after pymetrozine was sprayed according to the GAP standard of the United Kingdom.

\section{Materials and Methods}

A formulation containing 25\% pymetrozine WP (CHESS $\mathrm{WP}^{\circledR}$ ) was purchased from Syngenta Korea Inc., Republic of Korea. The reference standard for pymetrozine (purity, 99.9\%) was obtained from Dr. Ehrenstorfer (Augsburg, Germany). Methanol, dichloromethane, ethyl acetate, and 
<smiles>CC1=NNC(=O)N(N=Cc2cccnc2)C1</smiles>

Fig. 1 Chemical structure of pymetrozine

other solvents used were of analytical grade; anhydrous sodium sulfate was graded as being extra pure. The experimental field under a vinyl house was located in Yangchon, Nonsan City, Chungnam Province, Korea. The field grown A. scaber was divided into nine $15-\mathrm{m}^{2}$ plots. A complete randomized block design was applied with three replicates. The treatments were the following: untreated control (water only), standard dose of $200 \mathrm{~g}$ a.i. $\mathrm{ha}^{-1}$, and double dose of $400 \mathrm{~g}$ a.i. ha ${ }^{-1}$ CHESS WP ${ }^{\circledR}$. The spray volume was $3.5 \mathrm{~L} 15 \mathrm{~m}^{-2}$. After spraying, representative $A$. scaber plants were collected at 0 ( $2 \mathrm{~h}), 1,2,3$, 5,7 , and 10 days. The samples were stored in a freezer at $-20^{\circ} \mathrm{C}$ until analysis.

\section{Hydromatrix Method}

A harvested A. scaber sample (10 g) was put into an Erlenmeyer flask with $60 \mathrm{~mL}$ methanol and $7 \mathrm{~mL} 0.05 \mathrm{M}$ borax buffer. The flask was shaken on a mechanical shaker (Vision Scientific Co., Ltd., Korea) for $1 \mathrm{~h}$ and then filtered under vacuum through a Buchner funnel. The container and filter cakes were washed with $30 \mathrm{~mL}$ methanol, and the extracts were combined. The sample was evaporated in a vacuum rotary evaporator (EYELA, Japan) at $40^{\circ} \mathrm{C}$ until the extract volume reached about $10 \mathrm{~mL}$, then $3 \mathrm{~mL}$ of saturated sodium chloride was added. The sample was loaded on an Extrelut refill pack filled with $12 \mathrm{~g}$ hydromatrix (Chem Tube-Hydromatrix, Varian, USA) and washed with $2 \mathrm{~mL} 0.05 \mathrm{M}$ borax buffer. After $15 \mathrm{~min}$, the column was eluted with $100 \mathrm{~mL}$ dichloromethane, then evaporated to dryness on a vacuum rotary evaporator at $40^{\circ} \mathrm{C}$.

\section{Liquid-liquid Extraction (LLE) Method}

An A. scaber sample (10 g) was extracted with $60 \mathrm{~mL}$ methanol and $7 \mathrm{~mL} 0.05 \mathrm{M}$ borax buffer, and filtered under vacuum through a Buchner funnel. The eluate was then evaporated in a vacuum rotary evaporator at $40^{\circ} \mathrm{C}$ to a volume of about $10 \mathrm{~mL}$, then transferred to a 1-L separatory funnel with dichloromethane $(4 \times 40 \mathrm{~mL})$ for LLE. For partitioning, saturated sodium chloride was added at 3 and $2 \mathrm{~mL}$ for the first and second partitioning, respectively. The organic phases were combined and evaporated to dryness with a vacuum rotary evaporator.
Cleanup

The dried extracts from the extractions were redissolved in $10 \mathrm{~mL}$ methanol/ethyl acetate $(7: 93, \mathrm{v} / \mathrm{v})$. A 1-mL aliquot of concentrated extract was applied to the FL SPE cartridge (florisil 1,000 mg, $6 \mathrm{~mL}$; Phenomenex USA). To remove impurities, the SPE cartridge was washed with $4 \mathrm{~mL}$ methanol/ethyl acetate $(7: 93, \mathrm{v} / \mathrm{v})$ and eluted with $8 \mathrm{~mL}$ methanol/ethyl acetate $(3: 7, \mathrm{v} / \mathrm{v})$. The eluate was evaporated to dryness in a vacuum rotary evaporator at $40^{\circ} \mathrm{C}$, and the residue was dissolved in $2 \mathrm{~mL}$ methanol/water $(2: 8$, $\mathrm{v} / \mathrm{v}$ ) for analysis by HPLC.

To compare recovery between the hydromatrix and LLE extraction methods, recovery studies were carried out (in triplicate) by fortification of pymetrozine at $0.5 \mathrm{mg} \mathrm{kg}^{-1}$ (10-times LOQ) and $2.5 \mathrm{mg} \mathrm{kg}^{-1}$ (50-times LOQ) using untreated $A$. scaber, respectively. The above extraction and cleanup procedures were applied for recovery studies. HPLC (SCL-10Avp DAD; Shimadzu, Japan) was used for the pesticide analysis. Separation was carried out on a Phenomenex Luna C8 column $(250 \times 4.6 \mathrm{~mm}, 5 \mu \mathrm{m})$ maintained at $40^{\circ} \mathrm{C}$. The mobile phase consisted of methanol/water $(3: 7, \mathrm{v} / \mathrm{v})$ at a flow rate of $0.8 \mathrm{~mL} \mathrm{~min}^{-1}$. The injection volume was $20 \mu \mathrm{L}$ and the best detection was attained at a wavelength of $298 \mathrm{~nm}$ with a $7.85 \mathrm{~min}$ retention time.

\section{Results and Discussion}

An external standard method was adopted in this experiment. A six-point calibration curve from 0.025 to $5.0 \mathrm{mg} \mathrm{kg}^{-1}$ (peak area vs. concentration) was constructed for quantitative analysis of pymetrozine. The linear equation was $y=130716 x+952.92\left(R^{2}=1.0000\right)$.

Pymetrozine was added to untreated control samples at two levels $\left(0.5\right.$ and $\left.2.5 \mathrm{mg} \mathrm{kg}^{-1}\right)$. For method validation, control and fortified samples were analyzed under the same conditions. The reported results are mean of three replicates, whereby the coefficient of variation (CV) was within $10 \%$. The results of the recovery studies are presented in Table 1. To compare chromatograms between LLE and hydromatrix, HPLC chromatograms are provided in Fig. 2. The limit of quantitation (LOQ) of pymetrozine in

Table 1 Comparison of recovery methods for pymetrozine from Aster scaber $(\mathrm{n}=3)$

\begin{tabular}{lll}
\hline $\begin{array}{l}\text { Fortified } \\
\text { level }\left(\mathrm{mg} \mathrm{kg}^{-1}\right)\end{array}$ & \multicolumn{2}{l}{ Mean recovery $( \pm \mathrm{CV})(\%)$} \\
\cline { 2 - 3 } & LLE & Hydromatrix \\
\hline 0.5 & $97.2 \pm 2.13$ & $81.6 \pm 8.69$ \\
2.5 & $86.3 \pm 3.02$ & $69.9 \pm 4.76$ \\
\hline
\end{tabular}


Fig. 2 HPLC chromatograms of Aster scaber treated with pymetrozine: a control for LLE; b control for hydromatrix; c recovery with LLE at $2.5 \mathrm{mg} \mathrm{kg}^{-1}$; $\mathbf{d}$ recovery with hydromatrix at $2.5 \mathrm{mg} \mathrm{kg}^{-1}$
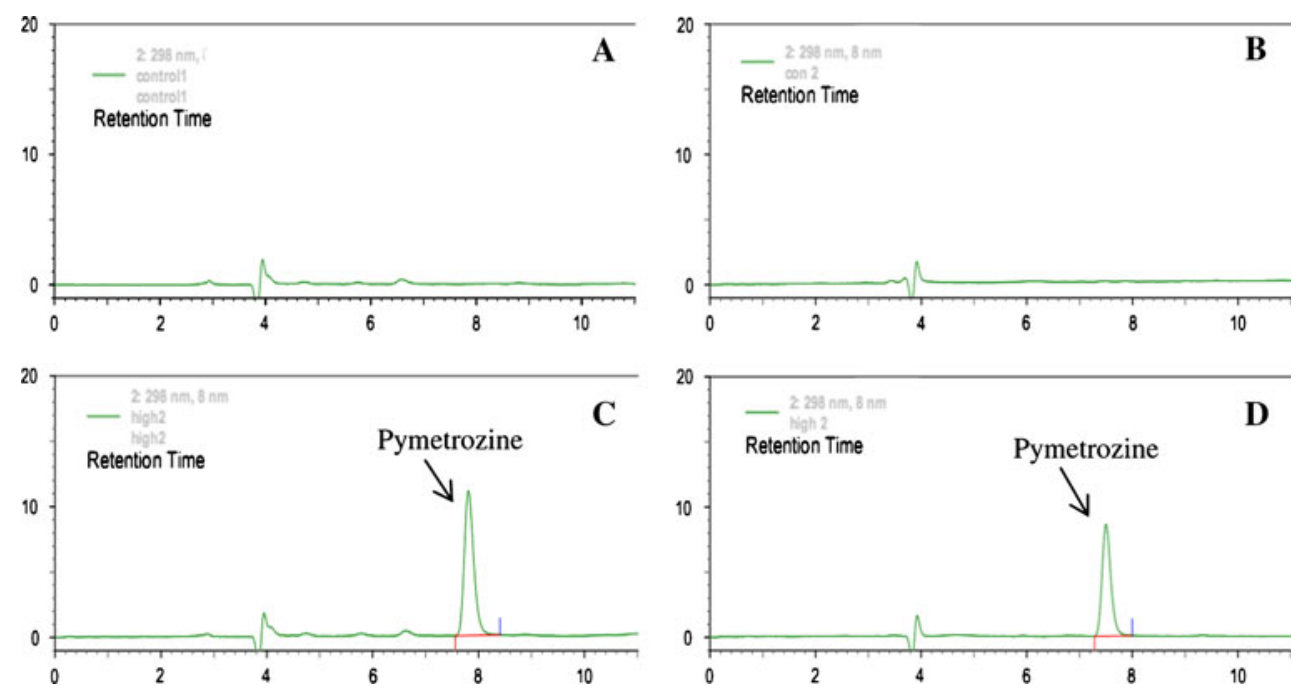

A. scaber was calculated as $0.05 \mathrm{mg} \mathrm{kg}^{-1}$ and the minimum detectable quantity was $5 \times 10^{-10} \mathrm{~g}$. Average recovery was higher with the LLE than the hydromatrix method, and the CV was more precise for the former.

Plant residue estimations for pymetrozine were carried out over 10 days following the spraying treatment. Initial $(2 \mathrm{~h})$ residues were 2.86 and $6.21 \mathrm{mg} \mathrm{kg}^{-1}$ at the recommended dose and double dose, respectively. Ten days after application, the remaining residues of pymetrozine were 0.60 and $0.79 \mathrm{mg} \mathrm{kg}^{-1}$; i.e., $79.02 \%$ and $87.28 \%$ of the initial residue levels had already dissipated. Figure 3 shows the change in pymetrozine residues for the seven sample times at 0-10 days after spraying. The kinetics of pymetrozine can be described with the following equations, $y=2.8706 \mathrm{e}^{-0.1644 \mathrm{t}}\left(R^{2}=0.9799\right)$ and $y=5.9791 \mathrm{e}^{-0.1996 \mathrm{t}}$ $\left(R^{2}=0.9950\right)$, and the biological half-life in A. scaber was 4.22 and 3.47 days at the recommended dose and the double dose, respectively.

The average weight of representative plant samples after $0-10$ days were $1.87 \pm 0.23 \mathrm{~g}(\mathrm{n}=20)$ at day 0 and increased to $4.78 \pm 0.41 \mathrm{~g}(\mathrm{n}=20)$ at day 10 . However, the average weight of representative $A$. scaber cultivated under the vinyl house differed according to cultivation date. Over 10 days, plant weight increased 2.56-fold from 17-27 May 2011 and 5.45-fold from 29 April to 9 May 2011 (NAQS 2011).

The pesticide dilution effect $\left(\mathrm{f}^{\prime}\right)$ was calculated from the remaining pymetrozine and weight of A. scaber over 10 days (Kim et al. 2009). For the three cases of considered growth rate, non-considered growth rate (NGR), 2.56-fold growth rate (Low Growth Rate, LGR), and 5.45-fold growth rate (High Growth Rate, HGR), the residue pattern in relation to growth at the double dose are given in Fig. 4. The biological half-life was 7.55, 3.47, and 1.91 days in the case of NGR $\left(y=5.3410 \mathrm{e}^{-0.0918 t}\right)$, LGR $\left(y=5.9791 \mathrm{e}^{-0.1996 \mathrm{t}}\right)$, and HGR $\left(y=6.8575 \mathrm{e}^{-0.3636 \mathrm{t}}\right)$,

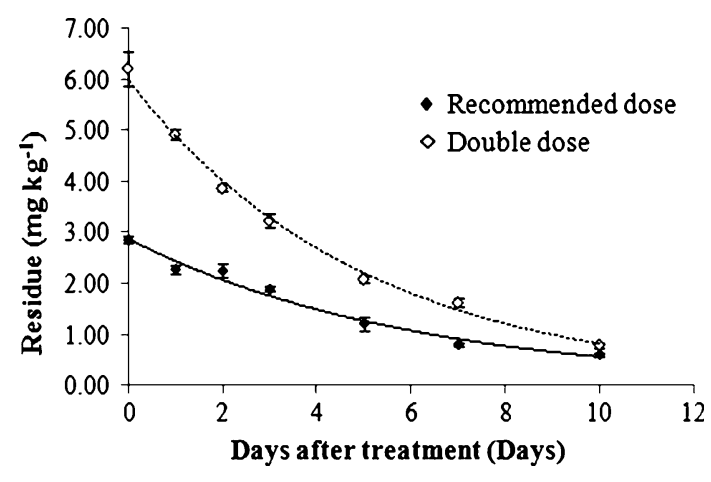

Fig. 3 Dissipation of pymetrozine in Aster scaber

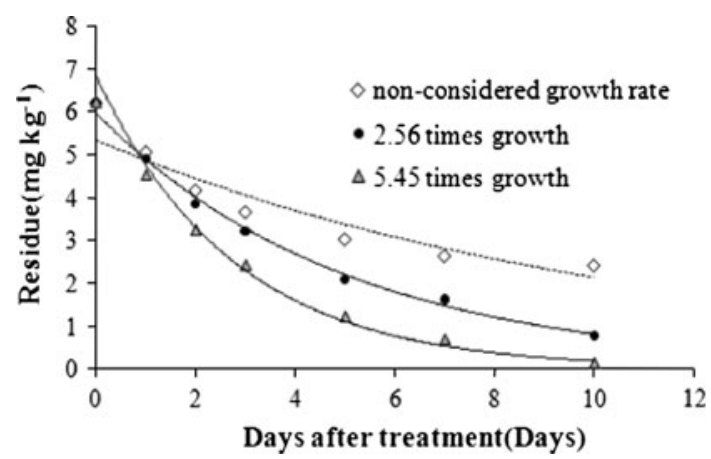

Fig. 4 Dilution effect of pymetrozine on Aster scaber in relation to growth rate

respectively. Therefore, the growth rate of A. scaber influences the residue levels of pymetrozine.

$f^{\prime}=\frac{\text { Residue at } 0 \text { days } \times \text { Weight of Aster scaber at } 0 \text { days }}{\text { Weight of Aster scaber at sample collection }}$

The rapid growth rate of cucumber will cause a dilution of pesticide residues over time, even if the pesticide does not degrade (Metwally et al. 1997). Moreover, Talebi and 


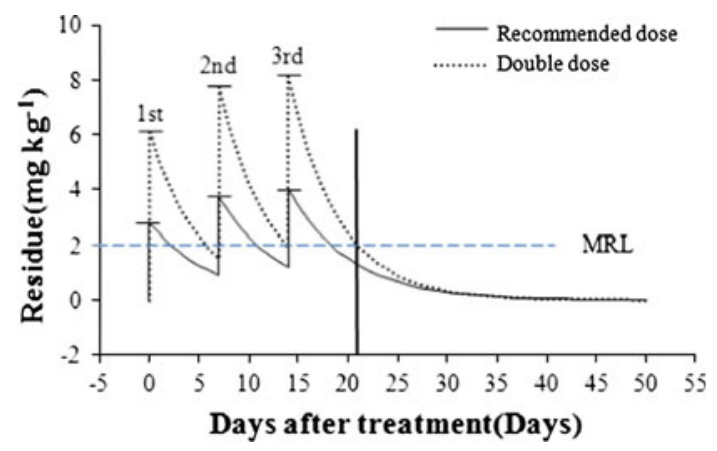

Fig. 5 Predicted final residue level of pymetrozine according to application amount

Ahsaii (2006) reported that no residues were detected in cucumber 4 days after spraying with pymetrozine under field conditions.

The final residue levels in A. scaber were compared when pymetrozine was sprayed according to the GAP standard of the United Kingdom for lettuce (application: three times at a spray interval of 7 days, and a maximum dose of $0.4 \mathrm{~kg}$ a.i. ha ${ }^{-1}$, PHI: 7 days). The prediction was calculated based on the initial amount sprayed and the coefficient of regression (Kim et al. 2009). Pymetrozine residues according to application amount are given in Fig. 5. After spraying with $1.2 \mathrm{~kg} \mathrm{ha}^{-1}$ (double dose, $0.4 \mathrm{~kg} \mathrm{ha}^{-1} \times 3$ ), the final residue level was predicted to be $1.98 \mathrm{mg} \mathrm{kg}^{-1}$ at harvest. After spraying with $0.6 \mathrm{~kg} \mathrm{ha}^{-1}$ (recommended dose, $0.2 \mathrm{~kg} \mathrm{ha}^{-1} \times 3$ ), the residue level was $1.28 \mathrm{mg} \mathrm{kg}^{-1}$. From this prediction, the pymetrozine residue on lettuce was below the maximum residue limit of the United Kingdom $\left(2 \mathrm{mg} \mathrm{kg}^{-1}\right) 7$ and 5 days after spraying with a double dose or the recommended dose, respectively.

Acknowledgments This study was financially supported by the National Agricultural Products Quality Management Services, Republic of Korea.
Open Access This article is distributed under the terms of the Creative Commons Attribution Noncommercial License which permits any noncommercial use, distribution, and reproduction in any medium, provided the original author(s) and source are credited.

\section{References}

Bextine BR, Harshman D, Johnson MC, Miller TA (2004) Impact of pymetrozine on glassy-winged sharpshooter feeding behavior and rate of Xylella fastidiosa transmission. J Insect Sci 4:34-39

Cun L, Ting Y, Weiguo H, Yinliang W (2011) Residue and dynamics of pymetrozine in rice field ecosystem. Chemosphere 82:901-904

Fuog D, Fergusson FJ, Fluckiger C (1998) Pymetrozine: a novel insecticide affecting aphids and whiteflies. In: 1shaaya I, Degheele D (eds) Insecticides with novel modes of action: mechanism and application. Springer, Berlin, pp 40-49

Guoqing S, Xuan H, Yinan H (2009) Kinetic study of the degradation of the insecticide pymetrozine in a vegetable-field ecosystem. J Hazard Mater 164:497-501

UK Health and Safety Executive (HSE) (2008) Maximum residue limit database. Available at http://www.secure.pesticides. gov.uk/MRLs/. Accessed 4 May 2011

Kim SW, Lee EM, Lin Y, Park HW, Lee HR, Riu MJ, Na YR, Noh JE, Keum YS, Kim JH (2009) Establishment of pre-harvest residue limit(PHRL) of insecticide Bifenthrin during cultivation of grape. Korean J Pesti Sci 13(4):241-248

Metwally MES, Osman MS, Al-Rushaid R (1997) A high-performance liquid chromatographic method for the determination of cypermethrin in vegetables and its application to kinetic studies after greenhouse treatment. Food Chem 59:283-290

National Agricultural Products Quality Management Services (NAQS) (2011) Deliberation on establishment of pre-harvest residue limit on products, Rep. of Korea, pp 277-294

Peter W, Martin B, Christian P (1996) Development of an enzyme immunoassay for the determination of the insecticide pymetrozine. Anal Lett. doi:10.1080/00032719608002257

Talebi K, Ahsaii HG (2006) Determination of pymetrozine residues in cucumber. Commun Agric Appl Bio Sci 71:75-78

US Environmental Protection Agency (EPA) (2000) Fact sheet. Available at http://www.epa.gov/opprd001/factsheets/pymetrozine. pdf. Accessed 4 May 2011

Zhang X, Cheng X, Wang C, Xi Z, Li Q (2007) Efficient highperformance liquid chromatography with liquid-liquid partition cleanup method for the determination of pymetrozine in tobacco. Annali di Chimica 97:295-301 